\title{
ЭКЗИСТЕНЦИАЛЬНЫЕ ОСНОВАНИЯ И ИСТОРИЧЕСКАЯ ДИНАМИКА МОТИВАЦИИ РЕЛИГИОЗНОЙ ВЕРЫ
}

\section{EXISTENTIAL FOUNDATIONS AND HISTORICAL DYNAMICS OF RELIGIOUS FAITH MOTIVATION}

A. Frolov

Summary: The article examines the existential foundations of the motives that convert a person to religious faith, which are defined as a historically dynamic phenomenon. The use of the provisions of the methodology of vitalism allows the author to interpret religion as one of the elements of the survival mechanism, which undergoes qualitative changes in the process of historical development. The article substantiates the position that the basic reason for historical changes in religion, including the motives of religious faith, is a change in the types of economic activity.

Keywords: existential foundations, motivation of religious faith, historical development of religion, pantheism, neopanteism, theism, historical type of economy.
$\mathrm{O}$ тправным пунктом обращения к религии в научном формате является ее определение как исторически динамичного явления. В научном анализе религии это тем более необходимо, что сознание современного человека испытывает крайне агрессивный прессинг со стороны различных конфессий, позиционирующих себя в категориях вечности и неизменности. Поэтому для исследования феномена религии принципиально важно не «боязливо оглядываться на церковное начальство и предание» $[1$, с. 88], а руководствоваться тем, что Ф. Ницше называл «интеллектуальной совестью» [2, с. 639].

Кроме этого, для плодотворного научного исследования религии необходим прочный и адекватный методологический фундамент. Автор данной статьи нашел этот фундамент в лице тех ключевых положений «философии жизни», которые ориентируют на понимание различных форм духовной активности прежде всего как «виталистски» направленной деятельности, а не в качестве проявлений «бескорыстного» поиска истины. Данные методологические положения дают ключ к правильной интерпретации не только общего вектора развития духовной сферы общества, но и к адекватному пониманию частных проблем духовного развития общества. Это относится ко всем видам духовной жизни, включая религию. «Виталистское» толкование феномена религии как механизма сохранения и развития жизни позволяет выстроить аргументированное объяснение основного

\author{
Фролов Анатолий Серафимович \\ Д.ф.н., профессор, Алтайский государственный \\ педагогический университет, г. Барнаул \\ asfrolof@mail.ru
}

Аннотация: В статье рассматриваются экзистенциальные основания обращающих человека к религиозной вере мотивов, которые определяются как исторически динамичное явление. Использование положений методологии витализма, позволяет автору трактовать религию в качестве одного из элементов механизма выживания, который в процессе исторического развития претерпевает качественные изменения. Обосновывается положение 0 том, что базовой причиной исторических изменений религии, включая мотивы религиозной веры, является смена типов хозяйственной деятельности.

Ключевые слова: экзистенциальные основания, мотивация религиозной веры, историческое развитие религии, пантеизм, неопантеизм, теизм, исторический тип хозяйства.

вектора исторической эволюции религии, развертывающейся от пантеизма, обожествления конкретных природных стихий и сущностей - к теистическому, персонифицированному пониманию Бога как «любящего Отца» и далее - к образу безличного Абсолюта как этически нейтральной первоосновы бытия.

Использование данной методологии позволяет обосновать следующее положение: такое направление исторического развития религии является не результатом действия тех или иных случайных факторов, а закономерным процессом. Содержание этого процесса определяется также закономерными изменениями в механизме сохранения и развития жизни, которые происходят в движении от доцивилизационной архаики, через древние цивилизации «осевой эпохи» - к техногенной цивилизации.

Автору этих строк уже приходилось обращаться к проблеме исторической эволюции религии и рассматривать ее в онтологическом, гносеологическом и экзистенциальном измерениях, в единстве которых эволюционирует религия, независимо от конкретной конфессии [3]. Учитывая задачи и рамки данной статьи, обратимся к экзистенциальному аспекту религии. Рассмотрение религии именно в этом аспекте позволяет вывести из потаённости, обнаружить и сделать зримыми наиболее глубинные переживания человека, его потребности, интересы, жизненно важные ценности и установки, - то 
есть всё то, что определяет обращение человека к той или иной конфессии и что составляет основное содержание мотивационной сферы религии.

Главные мотивы обращения к религии в доцивилизационной архаике определялись глубоким иррациональным ощущением неразрывного единства человека с Космосом, Природой. Человек архаики, подобно младенцу в утробе матери, не чувствовал границы между собой и природной средой. В процессе взаимодействия с Природой этот синкретизм восприятия субъективного и объективного, к которому применимы активно используемые С. Грофом понятия «трансперсонального» и «холотропного», [4] был прочным психологическим фундаментом уверенности архаичного человека в своих силах. Имевшее место чувство страха носило локальный характер и было связано лишь с теми явлениями, которые выходили за рамки повседневной практики выживания и неизвестная суть которых порождала ощущение угрозы. Не переживание страха, а иррациональное чувство сопричастности человека в отношениях с величественными, таинственными силами Природы было основным мотивом обращения к сакральному.

В процессе развития взаимодействия человека со средой обитания происходит изменение механизма выживания и являющегося его ядром типа хозяйственной деятельности. Основным фактором, определившим качественную трансформацию мотивов религиозной веры и пантеистического сознании явилась «неолитическая революция», переход от пассивного, присваивающего типа хозяйства (охота, рыболовство, собирательство) к активному, производящему типу (скотоводство, земледелие). Для психологии и сознания человека этот переход имел два «революционных» следствия:

1. Принципиальное возрастание потребности в позитивном, рациональном, логически оформленном знании о природе, без которого производящий тип хозяйства невозможен по определению. Начинается движение от Мифа к Логосу.

2. Преодоление синкретизма мифологического мышления, характерного для него отождествления субъективного и объективного. Формируется индивидуальное, личное сознание. Человек из существа, органично погруженного в среду обитания и составляющего с ней единое целое, эволюционирует в существо, осознающее себя в качестве субъекта деятельности, направленной на природу как объект.

Такая трансформация сознания имела важную драматичную составляющую, определяющуюся тем, что впервые в изменяющейся картине мира «природа выступает как поле действия безличных, чуждых и противоположных субъекту сил» [5, с. 76]. На смену органичному сосуществованию человека с Матерью-Природой приходит отношение к Природе как внешней грозной и противостоящей силе. Апогеем в осмыслении драматичного положения человека в мире природных стихий явилась «осевая эпоха». Её содержание К. Ясперс определил следующим образом: «Человек осознает бытие в целом, самого себя и свои границы. Перед ним открывается ужас мира и собственная беспомощность. Стоя над пропастью, он ставит радикальные вопросы, требует освобождения и спасения» [6, с. 33]. Таким образом, в «осевую эпоху», связанную с переходом к производящему типу хозяйства, страх превращается в основной, определяющий мотив религиозного самоопределения человека.

В этих принципиально изменившихся условиях потенциал пантеизма как психологического и духовного элемента сохранения и развития жизни оказывается недостаточным для того, чтобы нейтрализовать и компенсировать рожденное «осевой эпохой» ощущение ужаса и беспомощности человека. Драматизм «осевой эпохи» создает экзистенциальные предпосылки и основания для перехода от пантеистического типа религиозности к теистическому, в котором сакральное из безличной и нравственно нейтральной силы трансформируется в этически ориентированную Личность, в высшее проявление «любви и добра». Этот процесс не был одномоментным и имел противоречивое содержание, определяемое многообразием природно-климатических, географических, этнических, исторических, и иных условий. Этим обстоятельством объясняется наличие широкого диапазона оценок данного перехода. Например, Ф. Ницше определял утверждение христианства в качестве одной из разновидностей теизма как «редукцию божественного» и «противоестественную кастрацию божества в божество только добра» [2, с. 644, 642].

Но если абстрагироваться от субъективных пристрастий, то нельзя не признать, что для человека, психологически «Выпавшего» из состояния органической целостности в отношениях с Природой, теистический тип религии явился наиболее оптимальным способом преодоления чувства ограниченности и беспомощности. Подобно тому, как у появившегося на свет младенца существует потребность в защите со стороны любящего отца, у «родившегося» в «осевую эпоху», нового человека, мыслящего не мифологически, а логически, возникает объективная потребность в аналогичной защите.

В этой связи уместно привести следующие слова 3. Фрейда: «Что касается религиозного чувства, то его происхождение от детской беспомощности и пробужденной ею тоски по отцу представляется мне несомненным» [7, с. 246]. Хотя основоположник психоанализа в данном случае имел в виду не только теизм, а «религиозное чувство» как таковое, тем не менее, эти слова относятся в первую очередь к теистическим религиям. 
Именно в личностно понимаемом Боге, в «Боге живом», в «Боге Авраама и Исаака», рожденном теизмом, обрел человек необходимую психологическую опору и средство преодоления страха, - чувства, под прессингом драматизма «осевой эпохи» сменившего локально-эпизодический статус на универсально-тотальный. Именно в этом и состоит исключительно высокая роль теистических религий как средства сохранения и развития жизни в рассматриваемых условиях.

В теистических религиях страх играл и продолжает играть роль определяющего мотива и экзистенциального основания религиозности. Эта доминанта мотивации религиозной веры распространяется на всю историю религии данного типа. Изменяются лишь формы страха. Обозначая человеческую душу как «фабрику страха», а тревогу как «жало страха», протестантский теолог и философ П. Тиллих выделял в духовной истории человечества три вида тревоги, соотнося их преимущественно с какой-либо эпохой: «онтическую», «нравственную» и «духовную». «Онтическая» тревога, связанная со страхом судьбы и смерти, преобладала на этапе поздней античности. «Нравственная» тревога порождалась страхом вины и осуждения и господствовала в эпоху позднего средневековья. «Духовная» тревога, которая являлась выражением страха пустоты и отсутствия смысла, доминировала на закате Нового времени [8, с. 30-48].

Теистический тип религиозности явился самым органичным для человека, который находился между ступенями «младенчества» и «взрослости». Но вступив в период зрелости, в Новейшую историю, человек оказался в принципиально иных условиях, перед лицом новых проблем, необходимым условием решения которых стал выход религии за рамки теизма, неразрывно связанного с мотивом страха.

Симптомы кризиса религии теистического типа стали проявляться не сегодня. Одним из наиболее громко озвученных диагнозов вступления теизма в период качественного обострения с изменяющимися историческими условиями является декларация Ф. Ницше «Бог умер!» Но самым ярким по форме и ёмким по содержанию в этом плане является религиозный «бунт» героев произведений Ф.М. Достоевского. В связанной с этим бунтом экстатичной жажде «Бога живого», безнадежно упирающейся в стену многовекового глухого «молчания Бога», глубоко и убедительно выражаются конвульсии веры в личного Бога. В этом же обнаруживает себя и предчувствие нового, не по сектантски ограниченного, а фронтального движения к такому типу религиозности, который связан с неперсонифицированным образом Бога и который можно обозначить понятием неопантеизм.

Отсюда - используемая Ф.М. Достоевским и апеллирующая к «язычеству» формул «Богородица - великая мать сыра земля есть...» [9, с. 140], которая далеко не случайна и совершенно обоснованно может рассматриваться в качестве симптоматики кризиса религиозной веры теистического типа. Именно в «религиозном неврозе» героев Ф.М. Достоевского ярче и убедительнее всего проявляется надлом прежних экзистенциальных оснований религиозности - оснований, рождаемых универсальным страхом. Как справедливо отметил в этой связи В.Д. Захаров: «Но герои Достоевского не принимают такого Бога, которого человек выдумывает, чтобы обмануть самого себя - из собственной боли и страха перед небытием» [10, с. 94].

Это дает серьезные основания для того, чтобы к антиномии богопознания, сформулированной устами Кириллова и в творчестве Достоевского являющейся главной, подойти иначе, чем это в многочисленных исследованиях делалось до настоящего времени. «Бог необходим, а потому должен быть. (...) Но я знаю, что Его нет и не может быть», - утверждает Кириллов [9, с. 573]. Действительно, необходимость Бога как онтологического основания бытия является аксиомой. Но эмпирический опыт человечества (Кириллова в том числе), связанный с неопровержимым фактом вечного господства зла в Мире - более чем убедительно свидетельствует о том, что Бога как личности, как «любви и добра», нет и быть не может. В контексте такой интерпретации позиция Кириллова теряет статус антиномии и трансформируется В разрешимое противоречие. Его решение предполагает преодоление теистического, персонифицированного понимания Бога.

Религиозный «бунт» героев произведений Ф.М. Достоевского продолжился в духовных поисках русского Серебряного века. У «дионисийства» Вяч. Иванова, «нового религиозного сознания» Д.С. Мережковского, «языческого» бунтарства В.В. Розанова, - феноменов, имевших специфическую форму и содержание, вместе с тем, существовал и общий корень, - углубляющийся кризис религии теистического типа.

Современное общество породило новые страхи, связанные с угрозой мировой войны, экологического коллапса, терроризма, эпидемий новых вирусных заболеваний, с реальной опасностью полной утраты человеком приватности, глобальной «перезагрузки» социума в формате цифрового концлагеря и т.д. И, тем не менее, страх, как системообразующий мотив религиозной веры, сегодня исчерпал свой конструктивный потенциал. Господствовавшие в индустриальную эпоху технологии исключали глобальность последствий принимаемых человеком решений и предполагали возможность успешного исправления ошибок, - в чём человек как на психологический посох опирался на идею личного Бога и вытекающую из неё уверенность в «божьей помощи». 
Постиндустриальные технологии определяют глобальный характер последствий деятельности человека и принимаемых им решений. В таком высокотехнологичном мире теистический тип религии, внушающий надежду на «божью помощь», принципиально меняет свою роль, трансформируясь из положительного психологического фактора, повышающего уверенность в успехе, в средство, провоцирующее опасное снижение ответственности.

Доминирование страха в качестве основного мотива религиозного самоопределения личности в современных условиях качественно повышает возможность принятия безответственных решений, цена которых - с учетом современного технологического потенциала такова, что может поставить под вопрос существование человечества и свести на нет все позитивные плоды жизнеохранительных усилий предшествующих эпох. «Детство человечества» завершилось. По этой причине основным мотивом духовного выбора современного человека, включая религиозную веру, должен быть не страх, не надежда на поддержку и исправление ошибок со стороны «сакральных сил», а высочайшая ответственность за принимаемые решения и их последствия.

В современных условиях создаются предпосылки для такой трансформации духовной жизни, в которой происходит органический синтез актуализируемого духовного потенциала прошлых эпох и цивилизаций (включая мистические знания и практики) с достижениями современной науки. В таком контексте преодоление теизма и обращение на новой основе к пантеистическому типу религиозности - это не проявление субъективно-вкусовых пристрастий, а выражение объективной необходимости. И в свете такой эволюции религиозного сознания далеко не случайно появление в научной литературе публикаций, в которых происходит «реабилитация» и новое осмысление пантеизма [11]. Такие публикации не имеют никакого отношения к «неоязычеству», которое в последние десятилетия российской истории получило широкое распространение в массовой культуре.

В отличие от страдающей крайним дилетантизмом и клиповостью «неоязыческой попсы», новое переосмысление пантеизма продуктивно тем, что побуждает к глубокому осмыслению связей между содержащимися в древних учениях философскими и религиозными интуициями с современными, принципиально меняющими картину мира научными знаниями. В течение двух с половиной тысячелетий в философско-религиозных системах Древнего мира, Средневековья, Возрождения и Нового времени настойчиво утверждался образ божественного как безличного Абсолюта, первоначала бытия. Этому образу соответствует «Брахман» в учениях Древней Индии, «Дао» в даосизме, «мир идей» в философии Платона, «Единое» в неоплатонизме, natura non create creans» Эриугены, «natura naturans» Спинозы, «абсолютная идея» Гегеля и др. Такое понимание божественного удивительно созвучно, если не синонимично, понятиям «универсальное неперсонифицированное сознание», «космический разум», «семантический вакуум», «семантически насыщенный вакуум», «семантический континуум», - содержащимся в работах современных российских физиков В.В. Налимова и Л.В. Лескова $[12,13,14]$.

Фундаментальные научные открытия XX века, посвоему, усилили отразившийся в творчестве Ф.М. Достоевского и представителей Серебряного века пафос сомнений в адрес персонифицированного образа Бога, способствуя качественному углублению системного кризиса религии теистического типа. Многие известные учёные XX века открыто разделяли этот скептицизм. Так, по словам главного редактора научно-популярного британского журнала New Scientist Роджера Хайфилда, Эйнштейн, прямо отрицая личностный статус Бога, вместе с тем, утверждал: «Я верю в Бога Спинозы, проявляющим себя в упорядоченной гармонии того, что существует, а не в Бога, заботящегося о судьбе и деятельности человека» [15].

История мировой духовной культуры свидетельствует о том, что, являясь автономными системами знаний, наука и религия, вместе с тем, не изолированы друг от друга, и в конечном счёте, в их взаимоотношениях преобладает принцип координации, а не конфронтации. И есть основания предполагать, что утверждающаяся сегодня новая научная картина мира уже в ближайшей перспективе явится одним из важнейших факторов влияния на трансформацию содержания религии и мотивации религиозной веры в направлении преодоления теистического типа религиозности.

Утверждение на новой основе неперсонифицированного понимания Бога вовсе не исключает «диалогичности» в отношении «земного» и «небесного». Напротив, именно в рамках такого типа, с актуализацией имеющего непреходящую ценность опыта исторического развития различных религий и с утверждением ответственности человека в качестве основного побудительного мотива обращения к религии возникает возможность подлинной коммуникации человека и Абсолюта. Выходящий за рамки теизма Абсолют приобретает статус скрытого слоя реальности, непроявленного средоточия неограниченных возможностей, с овладением которыми связаны многообразные психосоматические практики, уходящие в тысячелетнюю историю. И в этой связи убедительно звучит следующая мысль, высказанная О.В. Вышегородцевой: «Пантеизм устраняет необходимость посредника между Богом и личностью, открывая бесконечные возможности интимного общения человека с Богом. Бог рядом с нами, вокруг нас, в нас...» [16]. 
С учётом возможностей, упоминаемых О.В. Вышегородцевой сформулированная А. Швейцером этика «благоговения перед жизнью» [17, с.304 - 340] из сентиментальной утопии, которой она является в рамках техногенной цивилизации, трансформируется в систему установок и ценностей, подобно «Декалогу» «Ветхого Завета» и «Нагорной проповеди Христа», способную оказывать конструктивное воздействие на все стороны жизни человека и общества. Есть все основания утверждать, что именно на этом пути находится возможность положительного выбора из альтернативы, сформулированной устами одного из героев Достоевского: «Добудьте Бога трудом... или исчезнете как плесень» [9, с. 243].

В контексте «неопантеистического» понимания Бога молитва как основной способ интимного общения с «Небесами» не является выпрашиванием «бесплатной», легкой и ни к чему не обязывающей «благодати». Подобно тому, как это имеет место во многих религиозных системах Востока, отрицающих личностный статус Бога, она - предельно ответственная психосоматическая, медитативная практика и большой труд, позволяющий из сакрального извлекать неисчерпаемые духовные, нравственные и физические возможности и силы.

Именно в границах нового пантеизма Бог, используя определения Уайтхеда, перестает быть «врагом», которым он неизбежно становится для тех, кто в действительности не находит подтверждения его личностного статуса как «любви и добра». Но, оставаясь «пустотой» (или в терминологии В.В. Налимова и Л.В. Лескова - «семантическим вакуумом»), в то же время Бог утверждается в религиозном опыте верующего как «спутник» [18, с. 347].

Определяя статус религии в современном информационном и высокотехнологичном мире, Дж. Сакс вполне обоснованно утверждал: «Религия остается главным фондом значимых вопросов о нашем существовании» $[19$, с. 20]. Характер развития современного общества позволяет с уверенностью экстраполировать данный статус религии и на будущее. Вместе с тем религия не может сохранить данный статус, оставаясь замкнутой на саму себя и равнодушной к современной общецивилизационной динамике, принципиально меняющей условия выживания человечества. Говоря о том, что одним из основных условий выживания является формирование нового «планетарного сознания», отражающего органичную связь человека с Природой, Космосом, Г.С. Киселев утверждает: «Но эта же задача (...) стоит и перед обновляющимся религиозным сознанием, которое без обновления или вообще исчезнет, или, в лучшем случае, останется на периферии человеческого общежития в качестве своего рода этнографического пережитка» [20, с. 180].

В современном духовном пространстве человечества активизируются переходные процессы, которые выражаются в принципиальной перестройке научной картины мира и развертывающимся кризисе традиционных религий, проявляющимся прежде всего в деформации их жизнеохранительных функций и коммерциализации. Сегодня человечество вступает в период, который можно назвать новой «осевой эпохой». Переход в течение тысячелетий к производящему хозяйству к началу «осевой эпохи» (VIII - II вB до н.э.) обусловил переход от мифологического к логическому мышлению и формирование предпосылок теистической религии. Происходящие сегодня радикальные изменения связанных с механизмом выживания технологий формируют предпосылки для рождения нового, - целостного сознания, в котором человек воспринимается не в усечённом формате клиповых построений, а в качестве органичной части Вселенной. В таких условиях страх как универсальный и преобладающий мотив деятельности человека и его религиозного самоопределения исчерпывает свой конструктивный потенциал.

Подобно тому, как рождение в «осевую эпоху» тотального страха привело к религии теистического типа, утверждение мотивов ответственности и того, что П. Тиллих обозначал понятием «мужество быть» [8], создают необходимые и прочные предпосылки для движения к религии «посттеистического» типа. А то обстоятельство, что такие радикальные изменения сознания затрагивают интересы многих людей и укоренившихся в структуре общества институтов, дает основание для вывода о том, что подобная трансформация религии и мотивов религиозной веры будет связана с множеством препятствий, проблем и противоречий и займёт целую историческую эпоху.

\section{ЛИТЕРАТУРА}

1. Франк С.Л. 0 невозможности философии. Русское мировоззрение. СПб.: Наука, 1996. - 736 с.

2. Ницше Ф. Антихрист. Проклятие христианству // Собр. соч. в 2-х т. Т. 2. - М., Мысль, 1996. - 829 с.

3. Фролов А.С. Феномен религии в контексте современного светского образования // Вестник психологии и педагогики Алтайского государственного университета. 2018. №1. - С. $76-107$.

4. Гроф С. Величайшее путешествие: Сознание и тайна смерти. М.: АСТ, 2008. - 475 С.

5. Найдыш В.М. Философия мифологии. От античности до эпохи романтизма. М.: Гардарики, 2002. - 554 с.

6. Ясперс К. Истоки истории и ее цель. Смысл и назначение истории. - М.: Политиздат, 1991. - 527 с.

7. Фрейд 3. Злободневное рассуждение о войне и смерти. Болезнь культуры. М.: АСТ, 2014. - 447 с. 
8. Тиллих П. Мужество быть. Избранное: Теология культуры. М.: Юрист, 1995. - 479 с.

9. Достоевский Ф.М. Бесы // Сочинения в 15 т. Т. 7. Л.: Наука, Ленинградское отделение, 1990. - 846 с.

10. Захаров В.Д. Размышления о природе веры. Дихотомия Бога // Вопросы философии. 2010. № 5. С. 91-104.

11. Гаджиев К.С. В защиту пантеизма // Вопросы философии. 2015. № 8. С. 191-202.

12. Лесков Л.В. На пути к новой картине мира [электронный ресурс] Режим доступа: URL: https://stihi.ru/2009/04/08/266 (дата 0бращения - 20.10.2021)

13. Лесков Л.В. Прорывные технологии XXI века мира [электронный ресурс] Режим доступа: URL: http://www.facets.ru/articles1/leskov.htm (дата обращения - 23.10.2021)

14. Налимов В.В. Осознающая себя Вселенная [электронный ресурс] Режим доступа: URL: https://web.archive.org/web/20111205183605/http://vnalimov.ru/ articles/111/395/ (дата обращения - 14.10.2021)

15. Highfield Roger. Hawking hasn't changed his mind about God [электронный ресурс] Режим доступа: URL: https://www.newscientist.com/article/dn19391hawking-hasnt-changed-his-mind-about-god/?ignored=irrelevant (дата обращения - 18.10.2021)

16. Вышегородцева 0.В. Пантеизм // Новая философская энциклопедия [электронный ресурс] Режим доступа: URL: http://iph.ras.ru/elib/2253.html (дата обращения - 14.10.2021)

17. Швейцер А. Культура и этика. М.: Прогресс, 1973. - 342 с.

18. Цит. по: Нибур Ричард. Радикальный монотеизм и западная культура // Христос и культура. Избранные труды Ричарда Нибура и Райнхольда Нибура. М.: Юрист, 1996. -575 c.

19. Сакс Дж. Границы секуляризации// Вопросы философии. 2013.№ 4. С. 20 - 27.

20. Киселев Г.С. Новая религиозность как проблема сознания // Вопросы философии. 2002. № 5. - С. 173-182.

() Фролов Анатолий Серафимович (asfrolof@mail.ru).

Журнал «Современная наука: актуальные проблемы теории и практики»

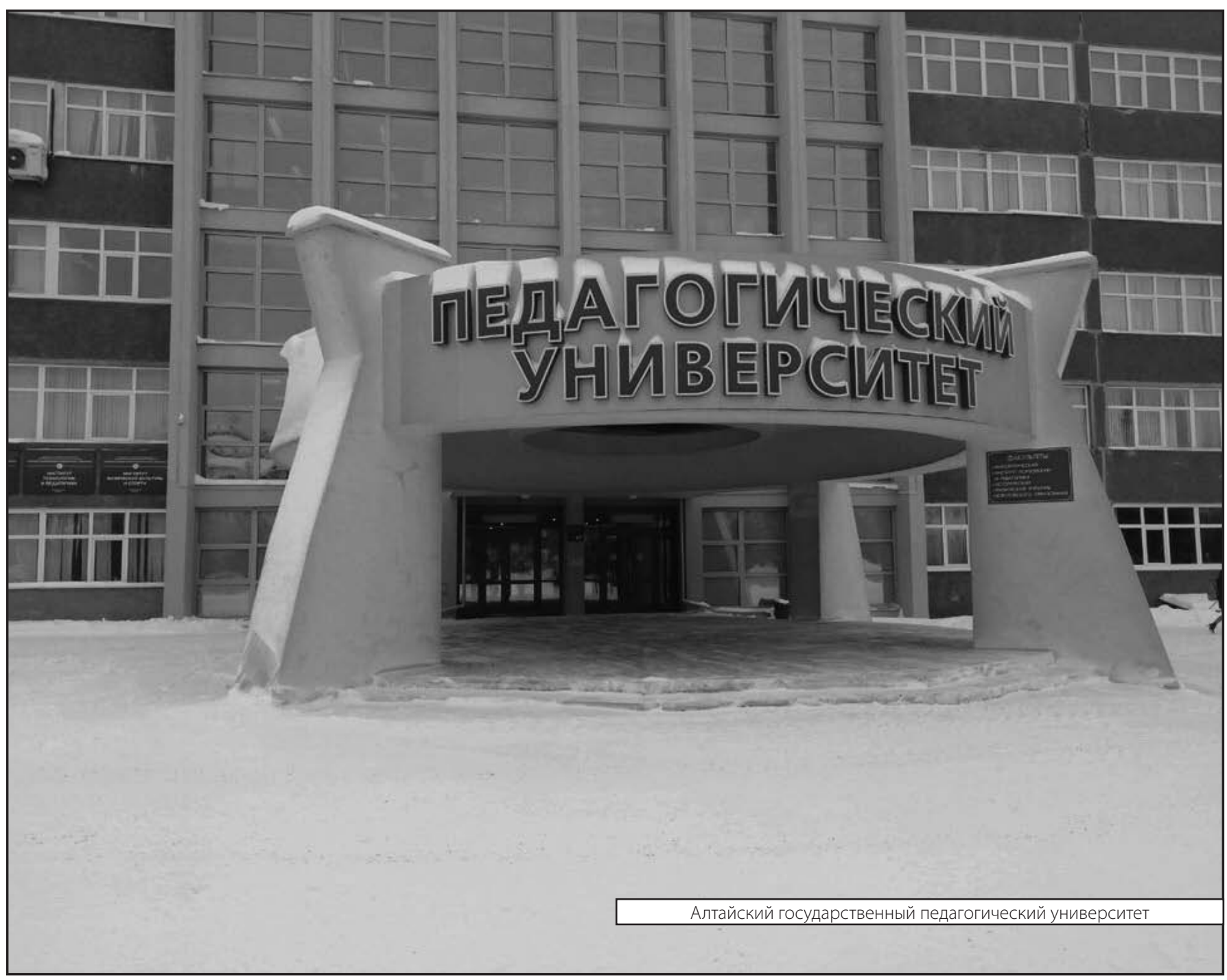

